\title{
Is adherence a relevant issue in the self-management education of diabetes? A mixed narrative review
}

This article was published in the following Dove Press journal:

Diabetes, Metabolic Syndrome and Obesity: Targets and Therapy 29 July 2014

Number of times this article has been viewed

\section{Xavier Debussche}

Endocrinology, Diabetology and Nutrition, CHU Félix Guyon, Saint-Denis, Réunion, France
Correspondence: Xavier Debussche Service de Diabétologie, CHU de la Réunion-Hôpital Félix Guyon, Allée des Topazes, Bellepierre, 97400 Saint-Denis, Réunion, France Tel +262262905610 Fax +262 262907718 Email xavier.debussche@chu-reunion.fr
Abstract: While therapeutic patient education is now recognized as essential for optimizing the control of chronic diseases and patient well-being, adherence to treatment and medical recommendations is still a matter of debate. In type 2 diabetes, the nonadherence to therapy, estimated at more than $40 \%$, is perceived as a barrier for improving the prognosis despite recent therapeutic advances. Interventional studies have barely begun to demonstrate the effectiveness of technical and behavioral actions. The aim of this review is to question the concept of adherence in terms of therapeutic education based on quantitative and qualitative data. The research on therapeutic education has shown the effectiveness of structured actions in type 2 diabetes, but adherence is rarely an end point in randomized trials. A positive but inconsistent or moderate effect of education actions on adherence has been shown in heterogeneous studies of varying quality. Program types, outlines, theoretical bases, and curricula to set up for action effectiveness are still being discussed. Qualitative studies, including sociological studies, provide a useful and constructive focus on this perspective. Adherence is a soft and flexible tool available to the patient in his/her singular chronic disease trajectory, and as such, integrates into individual therapeutic strategies, including socio-cultural interactions, beyond the medical explanation of the disease and the patient. Four key elements for the development of structured therapeutic education are discussed: 1) the access to health literacy, 2) the contextualization of education activities, 3) the long-term chronic dimension of self-management, and 4) the organizational aspects of health and care. Rather than focusing the objective on behavioral changes, structured therapeutic education actions should attempt to provide tools and resources aimed at helping individuals to manage their disease in their own context on a long-term basis, by developing health literacy and relational and organizational aspects of the health professionals and system.

Keywords: self-management, chronic disease, mixed research, health literacy, social context, lifestyle

\section{Introduction}

Therapeutic patient education, or self-management education (SME), is now recognized as essential for optimizing the control of chronic diseases and helping patients to manage their lives as effectively as possible. ${ }^{1}$ However, the medical community remains powerless when faced with the findings that more than $50 \%$ of chronically treated patients do not take the prescribed medications or do not follow the lifestyle measures that have been recommended to them; a phenomenon referred to as medication nonadherence. ${ }^{2}$ In numerous retrospective studies on diabetes, poor adherence or nonadherence have been associated with poorer glycemic control, ${ }^{3,4}$ a higher occurrence rate of complications and disability, and higher health care costs and mortality. ${ }^{5-8}$ Poor adherence to medications is common in type 2 diabetes (T2D), estimated 
at $40 \%-50 \%$, varying greatly depending on the studies and definitions. ${ }^{4,9,10}$ Extensive clinical trials have clearly shown that a strict glycemic and risk factor control could prevent or delay the onset of diabetes complications. ${ }^{11,12}$ After a long asymptomatic latent stage, the progressive intensification of treatment and medical monitoring is usual, together with the need for adapting dietary and physical activity practices. From a strictly medical perspective, the issue of adherence to health practices, prescribed treatments, and attendance to regular medical and paraclinical monitoring remains crucial. ${ }^{13}$ However, this is far from simple. The actual effectiveness of antihyperglycemic treatments remains limited and controversial, ${ }^{14}$ and the therapeutic strategy in diabetes should be integrative, aiming at the overall control of the risk factors for microvascular and macrovascular complications. The adherence issue highlights the difficulty, for the physician and for the patient, to manage and control the need for, and the consequences of, long-term treatment with all its potential implications. Treatment can often be effective on a short- or medium-term basis, but is possibly detrimental due to adverse events, especially on a long-term basis. ${ }^{5,15} \mathrm{~A}$ patient-centered approach is now at the core of the expert group recommendations:

... but given our uncertainties in terms of choice or sequence

of therapy, [a patient-centered approach] is particularly

appropriate in type 2 diabetes. ${ }^{16}$

In the most recent recommendations from the American Diabetes Association and International Diabetes Federations, diabetes SME (DSME) has been defined as the "ongoing process of facilitating the knowledge, skill and ability necessary for diabetes self-care". ${ }^{17,18}$

The overall objectives of DSME are to support informed decision making, self-care behaviors, problem solving, and active collaboration with the healthcare team and to improve clinical outcomes, health status, and quality of life. ${ }^{18}$

Theoretically, SME should address the multiple potential barriers to adherence described in chronic diseases: socioeconomic factors, factors related to the health care system and professionals, factors related to the disease, factors related to the treatment, and factors related to the patient. ${ }^{19,20}$ As such, adherence appears to be a complex but nevertheless restricted concept, relying on the medical treatment or recommendations, even if "patient-centered". Therefore, one may question the relevance of adherence as an issue, objective, or even an outcome in SME. The aim of this narrative review based on a systematic literature search is thus to analyze the relationships between SME and adherence in $\mathrm{T} 2 \mathrm{D}$, and the relevance of focusing SME on individual lifestyle, medication, and adherence recommendations. The objective is to rely on various quantitative and qualitative data to draw an integrative perspective on adherence-related issues in SME. First, the adherence issue and the current research highlights in DSME are presented, then the relevance of the adherence concept in therapeutic education is questioned based on data from qualitative and sociological studies. Finally, options for setting up perspectives for integrated and structured therapeutic education programs are suggested.

\section{Methodology}

The literature search (1990-2013), in English and French languages, was focused on the issue of adherence in SME in T2D or in chronic diseases, searching for systematic reviews and meta-analyses published in medical and paramedical journals (PubMed, Cochrane, CINAHL, Pascal). The following keywords were used, combined with T2D or chronic disease: self-management (or self-care or patient) education, adherence, compliance, medicine use, medication, or lifestyle. The literature search was then focused on qualitative research, meta-syntheses, and meta-ethnography articles carried out in the field of social sciences (SOCindex, Francis, ERIC, contents of the journals Social Science and Medicine, Sociology of Health and Illness, Qualitative Health Research, and Health Education and Behaviour). The following keywords were used: chronic disease, chronic illness, diabetes, adherence, medications, self-management, self-care, and treatment. After the selection based on titles and, when necessary on abstracts, full texts of all systematic reviews, meta-analyses, qualitative meta-syntheses, or metaethnographies were selected and analyzed when focusing on the issues of SME and adherence, primarily in the field of T2D, but without excluding other chronic diseases when it was considered relevant to the integrative topic of adherence in SME. Other articles (reviews or original research articles) from the reference lists of the selected articles were selected when necessary and articles from the personal reference list of the author of this review were included. Finally, 164 articles were selected, including 59 qualitative research articles. The aim of the review was to extract and synthesize quantitative results from systematic reviews and meta-analyses on SME and adherence intervention, and to compare them to qualitative data from research syntheses in the field of social sciences, in order to explore the relevance of adherence as an issue and an outcome in DSME, and finally to stress potential options for SME actions and structuring. 


\section{Effectiveness and outcomes of structured education programs}

Many randomized comparative studies on SME in T2D have been conducted. Initial intensive educational activities have shown overall a positive but variable effect on glycemic control through glycated hemoglobin $\left(\mathrm{HbA}_{1 \mathrm{c}}\right)$, the primary end point assessed in most studies. ${ }^{21-32}$ Positive impacts on self-management practices and quality of life have also been demonstrated in some studies. ${ }^{21-24}$ It has been shown that the higher the initial $\mathrm{HbA}_{1 \mathrm{c}}$ is, the greater will be the effect of $\mathrm{SME},{ }^{25}$ and that the total effective education time improves the overall results of these actions. ${ }^{23,26,27}$ The question of long-term maintenance of the positive impact of education activities is still being discussed, ${ }^{22,28}$ although longer effects are shown in patients who participated in group education programs. ${ }^{29,30}$ The currently available data show the need for testing structured and replicable group approaches with long-term educational multidisciplinary support, based on precise theoretical bases and adapted to different populations and cultures. ${ }^{23,31}$ SME structuring involves the need for clarifying processes, programs, and methods with written curricula and repeatable, assessable, and useful processes for the progress of research issues related to education actions. Quality programs should be evidence-based and carried out by trained, dynamic, and flexible professionals in order to adapt to individual needs and support patients in terms of behavior and practices, beliefs, knowledge, and self-management skills. ${ }^{32}$ However, the program structuring is highly variable. The recently published American Diabetes Association recommendations have stressed, among the fields requiring research actions, the unknown actual impact of the use of a structured curriculum in SME. ${ }^{18}$

\section{Adherence as an outcome in interventional studies}

The effect of interventions aimed at improving adherence remains moderately conclusive, with low or modest effects in the few rigorous studies carried out. ${ }^{33}$ Highly variable results have been obtained from different studies and are due to several factors: highly different assessment methods, ways to express the results (mean rate versus distribution), and also patient history in the context of their disease and care process, namely "recent" versus "experienced" patients. ${ }^{9,20}$ A clear distinction should be noted between, on one hand, the regular or irregular intake of a daily treatment and, on the other hand, the persistence of which reflects the treatment continuity after its initiation, even if not taken in accordance with the prescriptions. ${ }^{34}$ Three main patterns are described: primary nonadherence, non-persistence, and noncompliance or poor execution. Nonadherence is primarily observed during the first year of treatment in patients with chronic disease, but persistence remains poorly studied. ${ }^{19,34,35}$ This is especially true in T2D, where oral antidiabetic prescription and intake at disease diagnosis are poorly prepared or supported, unlike insulin therapy initiation..$^{20} \mathrm{~A}$ number of strategies seem poorly adapted to nonadherent patients at the onset of the disease, or early in the course of the disease, and a high proportion of nonadherent patients discontinue their treatment shortly after its first administration or do not follow their treatments. ${ }^{10}$

The typology of interventions used and tested is abundant and not always adapted to the conditions, contexts, and circumstances in which individuals and interventions are embedded. Most studies on medication intake left a passive role to the patient-consumer, including a poor or rarely developed knowledge and decision-making ability for taking treatments safely and effectively. ${ }^{36}$ There are three main types of interventions: technical (ease of use: packaging, schedules, doses, etc), behavioral (reminders, incentives, etc), and educational. ${ }^{37,38}$ Although the three types of interventions, alone or in combination, have been shown to improve adherence, the theoretical bases and types of truly effective interventions remain unclear. Reminders or dosing organizers do not seem relevant at some stages of T2D. ${ }^{38}$ In addition, no study has prospectively assessed the association of reminders or organizers with the improvement of health outcomes. ${ }^{35,37}$

Conversely, in most educational interventional studies, adherence was not the primary end point. Wens et al analyzed the detailed descriptions of eight educational programs included in the Cochrane review of comparative studies on medication adherence in T2D. ${ }^{39} \mathrm{~A}$ small positive overall effect was shown, but the actual clinical impact remained unclear: little evidence allowed for the identification of which type of educational intervention, or which part of complex interventions was the most effective. Regarding medication adherence, the pharmacist could play a particular role in education programs. Dedicated studies have shown a moderate positive effect of programs involving pharmacists on metabolic control but the effects on adherence were also mixed. ${ }^{40,41}$ The adherence to treatment or to activities related to lifestyle (diet, physical activity) is generally not assessed as such, but is integrated into self-management behaviors or self-care activities, although overall positive results of educational intervention studies of self-management behaviors have been reported in diabetes..$^{22}$ They mainly included data on physical activity and 
diet, with long-term changes reported in very few studies. ${ }^{29}$ The recent Cochrane review on the adherence to diet recommendations in chronic diseases only offered six inconclusive studies on diabetes. ${ }^{42}$ The effects of tailored interventions based on an initial assessment of patient needs in diabetes were disappointing in terms of adherence to self-monitoring practices, diet, or physical activity. ${ }^{43}$ The relationship between self-management behaviors and other criteria, including clinical and biological criteria and especially the $\mathrm{HbA}_{1 \mathrm{c}}$ level in diabetes, is complex. Moderate changes in physical activity or diet practices may occur while no obvious effect may be observed for biomedical outcomes. ${ }^{44}$ Conversely, in some studies, positive effects on clinical and biological outcomes were shown while no changes in self-care practices were observed. ${ }^{45,46}$ These findings reveal, on the one hand, the multifaceted health care practices potentially influencing biomedical outcomes with diverse thresholds for changing effects, and on the other hand, the heterogeneous and various modes of assessment or measurements of self-care activities between studies.

Thus, while adherence could be at least one of the intermediate or secondary end points in studies on the effectiveness of SME, it also lacks an established and universally accepted definition, based on data types, heterogeneous tools, and measurement methods. Although SME is now universally recognized as an essential component of T2D management, the effectiveness of educational interventions on adherence and the relationship between adherence and biomedical criteria still need to be clarified. ${ }^{39}$ In addition, randomized comparative studies cannot provide concrete results on the effectiveness of SME interventions on patients' everyday life, taking into account the experience of illness and interactions with health care providers. Quality of life and other patient-related outcomes may improve regardless of therapeutic adherence or worsen in case of good adherence (for example because of treatment-induced adverse events). The disease course may be favorable regardless of the treatment prescribed and adherence to that treatment. Finally, patients may very well manage their disease without "adhering" to all medications prescribed by their physician.

\section{Adherence: a relevant concept in structured patient education?}

One may therefore question the relevance in SME of the adherence concept as raised in daily medical practice. The study of adherence should necessarily take into account the medical complexity of variable effects of treatments taken individually, physician effects (adequacy of the therapeutic prescription, physician-patient relationship, etc), and associated activities prescribed and followed (or not). ${ }^{47}$ But it should also integrate individual and social complexity. Adherence is not a constitutive feature of individuals; it depends on the times in individual trajectory, disease history, treatment type, and of the various and evolving configurations and contexts.

\section{The trajectory of the chronic patient}

Social sciences have provided contributive findings concerning the trajectory of the chronic patient. ${ }^{48-50}$ Although they have not always focused directly on adherence, many studies implicitly questioned it in the context of chronic illness as early as the 1950s. Beyond the "sick role" theory of Parsons, which addressed the disease in general as a social "deviance" with rights and obligations for the ill person, ${ }^{51}$ sociological studies have focused on the importance of social interactions in the experience of patients with chronic illnesses and the trajectory of the patients themselves. ${ }^{52}$ The chronic patient must manage three different challenges: the disease itself (symptoms, diagnosis, management of "events", etc), everyday life, and "biographical work", referring to rebuilding his/her self-identity. ${ }^{52}$ Bury has described the "biographical disruption" corresponding to the emergence of chronic illness. The chronic patient experiences three stages: disease onset with needs for explanation and legitimization; the impact of the therapeutic process; and the development of adaptive resources. ${ }^{53}$ The latter itself involves three dimensions of actions and means: "coping", to tolerate the disease effects and maintain a perception of self-confidence; the strategy to alleviate the disease effects; and the "style" to respond to the disease and therapeutic procedures, for example by isolating from some social interactions or by emphasizing more or less the illness as a part of one's social identity. There is a wide range of homogeneous concepts between continuity and discontinuity along the trajectory of the chronic patient. ${ }^{54}$ Pound et al, and then Williams, in line with the work of Bury, have shown that the chronic illness does not necessarily cause a "disruption", but may also be one of the events in the continuity of a life with many other difficulties (social, economic, family, etc). ${ }^{55,56}$

\section{Social configurations and contexts}

The contexts (such as family) in which the disease meanings are negotiated by the individual play a major role. ${ }^{53}$ Charmaz, exploring the "self-identity loss" concept as a product of the interactions between the individual and others, emphasized the importance of the context of the individual faced with 
chronic illness and of social interactions. ${ }^{57}$ The chronic patient must face four dilemmas: restricted life, experience of social isolation, stigma from others versus his/her frustrated expectations, and finally threat to family members or close social environment because of the needs and demands for care related to the disease consequences. Rather than considering only the individual practices in terms of psychological features or particular history, health care practices may be analyzed as part of a combination between individual dispositions, which are associated with the socialization patterns that individuals are confronted with, and the social configurations in which they evolve, have evolved, or will evolve. ${ }^{58}$ The social contexts of a patient's life trajectory may have a strong impact on therapeutic and adherence decisions. ${ }^{59,60}$ The importance of understanding the complex factors involved in an individual patient's experience and its relationship with diabetes management have been clearly shown in cases of ethnic or cultural minorities. ${ }^{61-63}$ In these populations, beliefs and behaviors, the barriers usually suggested, are not the main factors to explain poor adherence, unlike structural and material barriers. ${ }^{64-66}$ Most patients are fully aware of the medical recommendations in terms of diet, physical activity, self-monitoring, and treatments. ${ }^{59,64,67}$ In diabetes, while the treatment usually aims at maintaining a correct glycemic control, patients identify a variety of constraints that influence the treatment, including constraints related to work, housing, family, their dependents, insecurity and financial difficulties, and roles differentiated according to sex. ${ }^{64}$ As part of selfcare activities, individuals are looking for a correct balance between health status and well-being. When the search for a better health status does not affect well-being, adherence to dietary and medical advice is not a problem. ${ }^{68}$ Poor adherence, beyond the difficulties associated with side effects and efficacy of the drug, is also related to self-regulation including testing, controlling dependence on others, on health professionals, and on medication, destigmatizing, and developing a "pragmatic practice". ${ }^{69}$ Although social and family support plays a central role in chronic patients' treatment, it may be ambiguous to develop individual strategies for coping with the disease. ${ }^{70}$

\section{Patient and provider perspectives}

Divergent perspectives on the disease and treatment between patients and health professionals do not facilitate adherence by opposing rational normative biomedical recommendations to meaningful individual stories, interpretations, and experiences. ${ }^{71}$ Patients and health care professionals do not share the same relationship with the disease in general, which is both eminently social and pathophysiological, and this distance persists even in case of demographic or cultural proximity. ${ }^{72}$ Taking multiple medications or the occurrence of several comorbidities raises doubts about the safety of the drug mix and about the complexity of drug-specific instructions. In this context, the individual's position and the suspicion toward medical professions in general, and pharmaceutical companies in particular, have an impact. The unanticipated chronic dimension of illness in general causes frustration in addition to the suspicion of treatment ineffectiveness, or the potentially more deleterious effect of distrust of medical discourses. ${ }^{62,73}$ However, Lawton et al showed the importance of the role of health care professionals at disease onset as experts influencing chronic illness trajectory. ${ }^{74}$ Patients perceiving chronic disease severity are reassured when their concerns are addressed to specialists. ${ }^{74}$

\section{Qualitative studies in self-management education}

Qualitative studies in chronic disease have highlighted the meanings that the illness can take for patients, and the importance of social and cultural contextualization in SME.${ }^{75}$ Chronic diseases require lifelong self-management. Decisions and opportunities do not necessarily make the patient trajectory linear when facing constraints, challenging beliefs and knowledge about the disease and treatment, and taking advantage from skills and strategies learned over time. ${ }^{60}$ The broad perseverance concept seems more appropriate here than the too-specific self-efficacy concept. ${ }^{76}$ The latter has been found as a key determinant for successful chronic disease self-management, especially in dedicated programs. ${ }^{77,78}$ However, to what extent self-efficacy is really independent of the capacities to self-manage the chronic disease remains to be determined, as well as if self-efficacy is really a cause and not a consequence of the adaptation to and coping with chronic disease. ${ }^{79}$ Education programs must not only be restricted to considerations of individual skills such as self-efficacy, while ignoring the multiple structural constraints of individuals (social position, sex, culture, etc). ${ }^{79,80}$

\section{Improving self-care and adherence}

The concept of adherence can thus be considered from a perspective that allows a full role for heterogeneous patient trajectories and their therapeutic strategies, including the medical explanation of the disease; the social interactions and contexts; the ownership and understanding of the underlying mechanisms and associated phenomena; and the relational 
and organizational aspects of the health care professional and system. Developing SME strategies and structuring will then benefit from integrating the complexity of related interactions and trajectories.

The first objective of SME is to maintain and improve health status and quality of life. It cannot be to modify behavior, even if it may be a contributory factor. Self-management per se is too complex to directly link behavior to biomedical indicators. ${ }^{81}$ The persons with diabetes are at the center of a whole support and educational process. They are responsible for the management of their illness day by day. The role of caregivers and educators is to make this management feasible and easier. ${ }^{18}$ Therefore, the primary objective of an intervention, activity, or therapeutic education program, is to try to make available to individuals the items, resources, and means or processes which will help them to progress in their own way and in their long-term or at least short- or medium-term contexts. Four key items can be individualized in thinking of the development of structured therapeutic education activities:

- The access to health knowledge and literacy.

- The contextualization of education activities and situations.

- The long-term chronic dimension of self-management.

- The organizational aspects of health and care systems and facilities.

\section{Access to, use, and building of knowledge: health literacy}

The perspective is no longer to think of the chronic patient as someone who must only become "adherent". The chronic patient is a person who has benefited from different socializations than those of the caregiver, who has different projects and values while daily experience of managing his/her disease. Health literacy is defined as an asset on which the individual can develop the capacities to live with and manage his/her disease and not as a cognitive or social limitation or deviance, or a risk factor for poor health status. ${ }^{82}$ Health literacy includes three areas: functional literacy, integrating reading and writing skills; interactive literacy, integrating cognitive and social skills used to participate actively in daily activities, extract information and deduce the meaning of different forms of communication, and apply new information to changing circumstances; and finally, critical literacy, referring to skills which can be applied to critical information analysis and to the use of this information for a better control of life events and situations. Functional literacy is often the only one emphasized, since disadvantaged people or people from different cultural and linguistic backgrounds are most often affected by chronic illness and struggle with disease management. It is certainly important to evolve functional health literacy, and to fully participate in community and health. ${ }^{83}$ Educational, individual, or group situations should take into account literacy levels (language, colors, images, reproductions). In parallel, the other literacy dimensions should be developed by stimulating and promoting interaction and implementing contextual confrontation in an educational situation and beyond in everyday life. ${ }^{84} \mathrm{~A}$ particular emphasis should be given in educational situations to the activity of the learners by developing an interactive and critical work. ${ }^{85}$ The experience and skills developed by a chronic patient are the result of testing in daily life and building from knowledge, including medical and technical knowledge, which must be updated and relevant. ${ }^{86,87}$ Here, the difficulty may be for the caregivers who are faced with two different logics: the logic of knowledge transmission to which they have been trained and the logic of complex knowledge building by patients. ${ }^{88,89}$ To give a real power of decision to the learner, the educator must necessarily take distance from the objective-based approach still mainly used in therapeutic educational practices. ${ }^{15,43,90}$

\section{Contextualization of educational situations: encourage the expression of social and cultural individual micro- contexts}

Patient education programs should, whenever possible, take into account the contextual dimension of learning and the perception that the patient environment may provide advantages or constraints. ${ }^{85}$ The education activities (carried out at the hospital, health center, physician practice, in associative facilities, etc) can almost never take place in the ordinary contexts of the individual whose health is at stake. The education program should enable the learner to work on the environment and to negotiate the properties of the environment in which any action takes place, helping him/her to study all possible configurations and identify the items to control. ${ }^{91-93}$ In the context of chronic disease, the individual must manage the uncertainty of its meanings and causes, in particular from a medical point of view, and what directly affects his/her life: symptoms, treatments with unclear effects, and hypothetical durations. $^{53}$

Thus, in an educational situation, as much as possible, the patient's ordinary and sociocultural contexts should be legitimized and visible and/or easy to handle (photographs, prints, diagrams, flyers, medication boxes, material, 
food, etc). Media used should be developed according to the cultural and environmental heterogeneity and represent the cultural and individual diversity (housing, food, clothing, religion, languages, etc). The learner patient may identify the "affordances" of his/her environment and continue to handle and develop his/her own context, identify through his/her practical experience the difficulties, eases, barriers, resources, supports, etc. Patient heterogeneity may be considered here as an asset for self-development and consideration of contexts. The role of peer educators (or expert patients) in a therapeutic education program should also be thought of in terms of experience and contextual development. This could allow more easily for the creation and promotion of a space for decision-making and for taking into account complex interactions beyond those of the patient-caregiver relationships. ${ }^{48}$

\section{The chronic dimension of self- management}

The education program should integrate the duration of the chronic disease and the need to consider strategies over the long-term. The decision-making is personal and faces social contexts and configurations which will allow the patient to reveal and express, or not, his/her dispositions. ${ }^{94}$ It implies that these decision-makings are potentially scalable, unfixed, and not subjected to a judgment or to the authority of health care professionals or other educators. This long-term patient work is the central challenge. ${ }^{95}$ The decision taken or developed for an action remains the patient's property, with an encouraged parallel space allowing the caregiver or the educator to improve patient psychosocial skills. The positioning of educational work in the overall health care process, related to health care and community health care professionals, teams, and system has to be real and visible. The educational work carried out in group sessions should be available remotely, legitimized, and reconsidered in the ordinary patient context, but also valorized in the medical context to integrate into the long-term trajectory of the disease management with its continuities and disruptions.

\section{Organizational aspects of the structuring}

The eminently social dimension of education programs should be acknowledged and taken into account. ${ }^{96,97}$ Several contextual concentric circles have a significant influence on the educational work methods integrated into the care process. ${ }^{85}$ These circles fall into at least three levels: the microsituational level (the education meeting: consultation with the patient-caregiver relationship, educational session, education group); the meso-contextual level (the peripheral dimension: health professional, care organizations, and structures); and finally the macro-contextual level (the health policy context, recommendations, and the community in its religious, cultural, linguistic, and economic dimensions).

\section{At the micro-situational level}

The program structuring itself should be adapted to the team resources and potentialities, by observing the progress of health care professionals themselves, while leaving a certain flexibility to patient trajectories, including to the possible nonadherence to education strategies themselves. Here the needs for structuring the teams may interfere with patient and trajectory heterogeneities. Objective- and agreementbased programs (tailored interventions, action plans) ${ }^{43,77,98}$ may be limited here in terms of patient self-management and support. Education situations and programs need to be improved and framed upstream by health care professionals and medical, paramedical, community health, and social sciences experts. ${ }^{86,99}$ Developing these structured educational situations thus prepares all the items to be developed by patients during the session(s): knowledge, context, action, and decision-making (or not). ${ }^{100}$ Programs need to be well supported by group interventions, without excluding individual educational meetings. Health care professionals (physicians, nurses, dietitians, pharmacists, medical, and sport educators) have here a crucial role, with the necessary change in attitude between the expert and the supporting educator. ${ }^{88,101}$ Further studies are needed to outline and closely analyze the role of expert patients, community health workers and other mediators together with health care professionals and educational teams, in particular among disadvantaged people with multiple comorbidities. The modalities of their interventions and their training requirements remain to be clarified. ${ }^{18,73,79,102,103}$

\section{At the meso-contextual level}

Several points are far from being clarified in practice. The interactions between care facilities, educational facilities, and other professionals or structures are most often absent or reduced to their simplest forms. Chronic patients who are self-building need easy access to medical, educational, social, or psychological expert professionals. ${ }^{104-106}$ The positive results of experiments on the care process integration focusing on the primary use of the general practitioner, such as the German diabetes management study in Germany ${ }^{107}$ or the chronic care model study in the US, ${ }^{108}$ have shown encouraging results. But these formalized systems may 
have the perverse effect of emphasizing the practitioner's expertise, without providing real responses to patient expectations and patients are at risk of becoming passive subjects "under supervision". ${ }^{109,110}$ New organizational implementation effects remain to be determined in the context of SME. ${ }^{18}$ To be active partners, patients need easy and flexible access to trusted professionals who respect their knowledge/ opinions about their disease and their preferences. ${ }^{111}$ If this accessibility and its visibility are absent, patients will be inclined to visit the emergency rooms which provide understandable, accessible medical and social assistance, in particular to the most disadvantaged. ${ }^{112}$ Health care (and social) system simplification, coordination, and visibility are essential for a real access and round-trip between self-care and support from professionals. ${ }^{106,113}$

\section{At the macro-contextual, institutional,} and political level

The challenge of chronic disease requires a multifaceted response to the trajectories, needs, and complex contexts. Overall, the current interventions and organizations very modestly impact the health status of chronic patients and the access to and use of adequate services. Recommendations that are too strict, or standardized, may impede the need for individual and social work on individual trajectories. Program and curriculum structuring is important in itself but its impacts remain unclear and poorly known. ${ }^{18,48}$ An important research initiative has yet to be developed on these points. Approaches should integrate patients, professionals, and health system organizations to better reflect the needs to respond to the chronic disease. ${ }^{114}$ Local appropriate responses must be developed according to the epidemiological, sociological, and local economic characteristics, based on the actual resources and professional fields. Expressing other ways to help chronically disadvantaged people such as community, voluntary activities, informal initiatives of patients, or patient groups, should not be neglected. Conversely, the legitimate needs to maintain conventional medical approaches, which are sometimes preferred by patients, should not be forgotten.

\section{Conclusion: beyond adherence, toward health literacy}

Various multidisciplinary studies carried out for more than 40 years in the field of adherence, SME, and chronic disease, and particularly in T2D, currently suggest a number of issues. Adherence, which is important for medically maintaining health status, can be considered as a soft and flexible tool at the patient's disposal in his/her chronic disease trajectory. Although adherence may be a useful indicator for assessing programs or research, it should not be considered as a monitoring and negotiation tool at the caregiver's disposal. Research, in particular in the social sciences, has shown that the listed problems raised by the chronic illness at the individual level depend primarily on diverse and evolving social contexts and configurations. There is therefore no single or standardized response. Strategies or responses for an individual to live with his/her chronic illness are multiple and cannot respond to a simple and unique prescription or recipe. Educational activities and program structuring are necessary to progress, improve, and develop reproducibility and studies on patient education. However, this structuring should leave the way open for individual trajectories and heterogeneous and particular contexts, avoiding strict protocols and accepting managing the situation and process complexity while respecting singular processes. Therapeutic education strategies do not immediately aim at changing behavior, but they should help people to improve their health literacy, which is seen as an asset on which the individual could work to develop the skills to live with and manage his/ her disease. Current progresses should integrate patients, all professionals, and institutions, and avoid compartmentalization and categorizations. Because of the complexity of these phenomena, the joint work in practice and research should not only rely on experimental, deductive, and quantitative medical and social sciences studies, but also on inductive and qualitative studies.

\section{Disclosure}

The author reports no conflicts of interest in this work.

\section{References}

1. World Health Organization. Therapeutic Patient Education. Continuing Education Programs for Healthcare Providers in the Field of Prevention of Chronic Diseases. Geneva: World Health Organization; 1998. Available from: http://www.euro.who.int/_data/assets/pdf_file/0007/145294/ E63674.pdf. Accessed February 15, 2014.

2. DeMaria AN. Adherence, compliance, concordance, or the lack thereof. J Am Coll Cardiol. 2012;59(12):1120-1121.

3. Asche C, LaFleur J, Conner C. A review of diabetes treatment adherence and the association with clinical and economic outcomes. Clin Ther. 2011;33(1):74-109.

4. Tiv M, Viel JF, Mauny F, et al. Medication adherence in type 2 diabetes: The ENTRED Study 2007, a French Population-Based Study. PLoS One. 2012;7(3):e32412.

5. Simpson SH, Eurich DT, Majumdar SR, et al. A meta-analysis of the association between adherence to drug therapy and mortality. BMJ. 2006;333(7557): 15 .

6. Ho PM, Rumsfeld JS, Masoudi FA, et al. Effect of medication nonadherence on hospitalization and mortality among patients with diabetes mellitus. Arch Intern Med. 2006;166(17):1836-1841. 
7. Sokol MC, McGuigan KA, Verbrugge RR, Epstein RS. Impact of medication adherence on hospitalization risk and healthcare cost. Med Care. 2005;43(6):521-530.

8. Pladevall M, Williams LK, Potts LA, Divine G, Xi H, Lafata JE. Clinical outcomes and adherence to medications measured by claims data in patients with diabetes. Diabetes Care. 2004;27(12): 2800-2805.

9. Cramer JA. A systematic review of adherence with medications for diabetes. Diabetes Care. 2004;27(5):1218-1224.

10. Fischer MA, Stedman MR, Lii J, et al. Primary medication nonadherence: analysis of 195,930 electronic prescriptions. J Gen Intern Med. 2010;25(4):284-290.

11. Gaede P, Lund-Andersen H, Parving H-H, Pedersen O. effect of a multifactorial intervention on mortality in type 2 diabetes. $N$ Engl $J$ Med. 2008;358(6):580-591.

12. Holman RR, Paul SK, Bethel MA, Matthews DR, Neil HAW. 10-year follow-up of intensive glucose control in type 2 diabetes. N Engl J Med 2008;359(15):1577-1589.

13. van den Arend IJM, Stolk RP, Krans HMJ, Grobbee DE, Schrijvers AJP. Management of type 2 diabetes: a challenge for patient and physician. Patient Educ Couns. 2000;40(2):187-194.

14. Boussageon R, Gueyffier F, Cornu C. Effects of pharmacological treatments on micro- and macrovascular complications of type 2 diabetes: What is the level of evidence? Diabetes Metab. Epub February 3, 2014.

15. Haynes RB, Ackloo E, Sahota N, McDonald HP, Yao X. Interventions for enhancing medication adherence [review]. Cochrane Database Syst Rev. 2008;2:CD000011.

16. Inzucchi SE, Bergenstal RM, Buse JB, et al; American Diabetes Association (ADA); European Association for the Study of Diabetes (EASD). Management of hyperglycemia in type 2 diabetes: a patient-centered approach: position statement of the American Diabetes Association (ADA) and the European Association for the Study of Diabetes (EASD). Diabetes Care. 2012;35(6):1364-1379.

17. International Diabetes Federation. Global Guideline for Type 2 Diabetes. Brussels: International Diabetes Federation; 2012. Available from: http://www.idf.org/sites/default/files/IDF-Guideline-for-Type-2Diabetes.pdf. Accessed February 12, 2014.

18. Haas L, Maryniuk M, Beck J, et al; 2012 Standards Revision Task Force. National standards for diabetes self-management education and support. Diabetes Care. 2014;37 Suppl 1:S144-S153.

19. World Health Organization. Adherence to long term therapies. Evidence for action. Geneva: World Health Organization; 2003. Available from: http://whqlibdoc.who.int/publications/2003/9241545992.pdf. Accessed January 25, 2014.

20. Kardas P, Lewek P, Matyjaszczyk M. Determinants of patient adherence: a review of systematic reviews. Front Pharmacol. 2013;4:91.

21. Steinsbekk A, Rygg LØ, Lisulo M, Rise MB, Fretheim A. Group based diabetes self-management education compared to routine treatment for people with type 2 diabetes mellitus. A systematic review with meta-analysis. BMC Health Serv Res. 2012;12:213.

22. Norris SL, Engelgau MM, Narayan KM. Effectiveness of selfmanagement training in type 2 diabetes: a systematic review of randomized controlled trials. Diabetes Care. 2001;24(3):561-587.

23. Deakin T, McShane CE, Cade JE, Williams RD. Group based training for self-management strategies in people with type 2 diabetes mellitus [review]. Cochrane Database Syst Rev. 2005;2:CD003417.

24. Duke SA, Colagiuri S, Colagiuri R. Individual patient education for people with type 2 diabetes mellitus [review]. Cochrane Database Syst Rev. 2009;1:CD005268.

25. Sigurdardottir AK, Jonsdottir H, Benediktsson R. Outcomes of educational interventions in type 2 diabetes: WEKA data-mining analysis. Patient Educ Couns. 2007;67(1-2):21-31.

26. Trento M, Passera P, Bajardi M, et al. Lifestyle intervention by group care prevents deterioration of Type II diabetes: a 4-year randomized controlled clinical trial. Diabetologia. 2002;45(9):1231-1239.
27. Brown SA, Blozis SA, Kouzekanani K, Garcia AA, Winchell M, Hanis CL. Dosage effects of diabetes self-management education for Mexican Americans: the Starr County Border Health Initiative. Diabetes Care. 2005;28(3):527-532.

28. Debussche X, Colin F, Fianu A, et al. Structured self-management education maintained over two years at the community level in insufficiently controlled type 2 diabetes patients: the ERMIES multicentre randomised trial in Reunion Island. Cardiovasc Diabetol. 2012;11:91.

29. Newman S, Steed L, Mulligan K. Self-management interventions for chronic illness. Lancet. 2004;364(9444):1523-1537.

30. Ko SH, Song KH, Kim SR, et al. Long-term effects of a structured intensive diabetes education programme (SIDEP) in patients with Type 2 diabetes mellitus-a 4-year follow-up study. Diabet Med. 2007;24(1):55-62.

31. Dinneen SF. Structured education for people with type 2 diabetes. $B M J$. 2008;336(7642):459-460.

32. Carrey M, Davies M, Khunti K. Supplying the misssing link in diabetes care: evidence-based structured education for people with type 2 diabetes. In: Vora J, Buse J, eds. Evidence-based Management of Diabetes. Shrewsbury, UK: TFM Publishing Limited; 2012:67-80.

33. Vermeire E, Wens J, Van Royen P, Biot Y, Hearnshaw H, Lindenmeyer A. Interventions for improving adherence to treatment recommendations in people with type 2 diabetes mellitus [review]. Cochrane Database Syst Rev. 2005;2:CD003638.

34. Guénette L, Moisan J, Breton MC, Sirois C, Grégoire JP. Difficulty adhering to antidiabetic treatment: Factors associated with persistence and compliance. Diabet Metab. 2013;39(3):250-257.

35. Osterberg L, Blaschke T. Adherence to medication. $N$ Engl J Med. 2005;353(5):487-497.

36. Ryan R, Santesso N, Hill S, Lowe D, Kaufman C, Grimshaw J. Consumer-oriented interventions for evidence-based prescribing and medicines use: an overview of systematic reviews [review]. Cochrane Database Systc Rev. 2011;5:CD007768.

37. Asante E. Interventions to promote treatment adherence in type 2 diabetes mellitus. Br J Community Nurs. 2013;18(6):267-274.

38. van Dulmen S, Sluijs E, van Dijk L, de Ridder D, Heerdink R, Bensing J. Patient adherence to medical treatment: a review of reviews. $B M C$ Health Serv Res. 2007:7:55.

39. Wens J, Vermeire E, Hearnshaw H, Lindenmeyer A, Biot Y, Van Royen P. Educational interventions aiming at improving adherence to treatment recommendations in type 2 diabetes. Diabetes Res Clin Pract. 2008;79(3):377-388.

40. Sarkadi A, Rosenqvist U. Experience-based group education in type 2 diabetes a randomised controlled trial. Patient Educ Couns. 2004;53(3): 291-298.

41. Machado M, Bajcar J, Guzzo GC, Einarson TR. Sensitivity of patient outcomes to pharmacist interventions. Part I: systematic review and meta-analysis in diabetes management. Ann Pharmacother. 2007;41(10):1569-1582.

42. Desroches S, Lapointe A, Ratté S, Gravel K, Légaré F, Turcotte S. Interventions to enhance adherence to dietary advice for preventing and managing chronic diseases in adults [review]. Cochrane Database Syst Rev. 2013;2:CD008722.

43. Radhakrishnan K. The efficacy of tailored interventions for selfmanagement outcomes of type 2 diabetes, hypertension or heart disease: a systematic review. $J A d v$ Nurs. 2011;68(3):496-510.

44. Debussche X, Rollot O, Le Pommelet C, et al. Quarterly individual outpatients lifestyle counseling after initial inpatients education on type 2 diabetes: the REDIA Prev-2 randomized controlled trial in Reunion Island. Diabetes Metab. 2012;38(1):46-53.

45. Rickheim PL, Weaver TW, Flader JL, Kendall DM. Assessment of group versus individual diabetes education: a randomized study. Diabetes Care. 2002;25(2):269-274.

46. Spencer MS, Rosland A-M, Kieffer EC, et al. Effectiveness of a community health worker intervention among African American and Latino adults with type 2 diabetes: a randomized controlled trial. Am J Public Health. 2011;101(12):2253-2260. 
47. Vermeire E, Hearnshaw H, Rätsep A, et al. Obstacles to adherence in living with type-2 diabetes: An international qualitative study using meta-ethnography (EUROBSTACLE). Prim Care Diabetes. 2007;1(1): 25-33.

48. Bury M, Newbould J, Taylor D. A Rapid Review of the Current State of Knowledge Regarding Lay-Led Self-Management of Chronic Illness: Evidence Review. London: National Institute for Health and Clinical Excellence; 2005. Available from: http://www.nice.org.uk/niceMedia/ pdf/lay_led_rapid_review_v10-FINAL.pdf. Accessed January 15, 2014.

49. Lawton J. Lay experiences of health and illness: past research and future agendas. Sociol Health Illn. 2003;25:23-40.

50. Gerhardt U. Qualitative research on chronic illness: the issue and the story. Soc Sci Med. 1990;30(11):1149-1159.

51. Parsons T. The Social System. Chicago: Free Press; 1951.

52. Glaser BG, Strauss AL. The Discovery of Grounded Theory: Strategies for Qualitative Research. Chicago: Aldine; 1967.

53. Bury M. Chronic illness as biographical disruption. Sociol Health Illn. 1982;4(2):167-182.

54. Armstrong D. The impact of papers in Sociology of Health and Illness: a bibliographic study. Sociol Health Illn. 2003;25:58-74.

55. Pound P, Gompertz P, Ebrahim S. Illness in the context of older age: the case of stroke. Sociol Health Illn. 1998;20(4):489-506.

56. Williams S. Chronic illness as biographical disruption or biographical disruption as chronic illness? Reflections on a core concept. Sociol Health Illn. 2000;22(1):40-67.

57. Charmaz K. Loss of self: a fundamental form of suffering in the chronically ill. Sociol Health Illn. 1983;5(2):168-195.

58. Lahire B. From the habitus to an individual heritage of dispositions. Towards a sociology at the level of the individual. Poetics. 2003;31(5-6): 329-355.

59. Balcou-Debussche M, Debussche X. Hospitalisation for type 2 diabetes: the effects of the suspension of reality on patients' subsequent management of their condition. Qual Health Res. 2009;19(8):1100-1115.

60. Campbell R, Pound P, Pope C, et al. Evaluating meta-ethnography: a synthesis of qualitative research on lay experiences of diabetes and diabetes care. Soc Sci Med. 2003;56(4):671-684.

61. Kelly M, Field D. Medical sociology, chronic illness and the body. Sociol Health Illn. 1996;18(2):241-257.

62. Bhattacharya G. Psychosocial impacts of type 2 diabetes selfmanagement in a rural African-American population. J Immigr Minor Health. 2012;14(6):1071-1081.

63. Debussche X, Roddier M, Fianu A, Le Moullec N, Papoz L, Favier F; REDIA Study Group. Health perceptions of diabetic patients in the REDIA study. Diabetes Metab. 2006;32(1):50-55.

64. Anderson JM, Wiggins S, Rajwani A, Holbrook C, Blue C, Ng M. Living with a chronic illness: Chinese- Canadian and Euro-Canadian women with diabetes - exploring the factors that influence management. Soc Sci Med. 1995;41(2):181-195.

65. Horne R, Graupner L, Frost S, Weinman J, Wright SM, Hankins M. Medicine in a multi-cultural society: the effect of cultural background on beliefs about medications. Soc Sci Med. 2004;59(6): 1307-1313.

66. Greenhalgh T, Helman C, Chowdhury AM. Health beliefs and folk models of diabetes in British Bangladeshis: a qualitative study. BMJ. 1998;316(7136):978-983.

67. Bissell P, May CR, Noyce PR. From compliance to concordance: barriers to accomplishing a re-framed model of health care interactions. Soc Sci Med. 2004;58(4):851-862.

68. Maclean HM. Patterns of diet related self-care in diabetes. Soc Sci Med. 1991;32(6):689-696.

69. Conrad P. The meaning of medications: another look at compliance. Soc Sci Med. 1985;20(1):29-37.

70. Gallant MP. The influence of social support on chronic illness selfmanagement: a review and directions for research. Health Educ Behav. 2003;30(2):170-195.
71. Schoenberg NE, Amey CH, Coward RT. Stories of meaning: lay perspectives on the origin and management of noninsulin dependent diabetes mellitus among older women in the United States. Soc Sci Med. 1998;47(12):2113-2125.

72. Cohen MZ, Tripp-Reimer T, Smith C, Sorofman B, Lively S. Explanatory models of diabetes: Patient practitioner variation. Soc Sci Med. 1994;38(1):59-66.

73. Mishra SI, Gioia D, Childress S, Barnet B, Webster RL. Adherence to medication regimens among low-income patients with multiple comorbid chronic conditions. Health Soc Work. 2011;36(4): 249-258.

74. Lawton J, Peel E, Parry O, Araoz G, Douglas M. Lay perceptions of type 2 diabetes in Scotland: bringing health services back in. Soc Sci Med. 2005;60(7):1423-1435.

75. Gomersall T, Madill A, Summers LK. A metasynthesis of the selfmanagement of type 2 diabetes. Qual Health Res. 2011;21(6):853-871.

76. Savoca MR, Miller CK, Quandt SA. Profiles of people with type 2 diabetes mellitus: the extremes of glycemic control. Soc Sci Med. 2004;58(12):2655-2666.

77. Lorig KR, Holman H. Self-management education: history, definition, outcomes, and mechanisms. Ann Behav Med. 2003;26(1):1-7.

78. Bandura A. Self-Efficacy: The Exercise of Control. New York: W. H. Freeman 1997.

79. Taylor D, Bury M. Chronic illness, expert patients and care transition. Sociol Health Illn. 2007;29(1):27-45.

80. Aujoulat I, Luminet O, Deccache A. The perspective of patients on their experience of powerlessness. Qual Health Res. 2007;17(6):772-785.

81. Thille P, Ward N, Russell G. Self-management support in primary care: Enactments, disruptions, and conversational consequences. Soc Sci Med. 2014;108:97-105.

82. Nutbeam D. The evolving concept of health literacy. Soc Sci Med. 2008;67(12):2072-2078.

83. Dewalt DA, Berkman ND, Sheridan S, Lohr KN, Pignone MP. Literacy and health outcomes: a systematic review of the literature. J Gen Intern Med. 2004;19(12):1228-1239.

84. Balcou-Debussche M. Littératie en santé et interactions langagières en éducation thérapeutique. [Health literacy and language interactions in therapeutic patient education]. Education, Santé, Société. In press 2014. French.

85. Balcou-Debussche M. [Therapeutic education: between complex knowledge, educators, heterogeneous learners and plural contexts]. Rech Soins Infirm. 2012(110):45-59. French.

86. Balcou-Debussche M. Une approche ethnosociologique de l'éducation thérapeutique du patient dans le diabète de type 2. [An ethnosociological approach of therapeutic patient education in type 2 diabetes]. In: Foucaud J, Bury J, Balcou-Debussche M, Eymard C, editors. Éducation thérapeutique du patient. Modèles, pratiques et évaluation. [Therapeutic patient education. Models, practices and assessment]. Paris: INPES; 2010:75-89. French.

87. Pols J. Knowing Patients: Turning patient knowledge into science. Sci Technol Human Values. 2013;39(1):73-97.

88. Lee RG, Garvin T. Moving from information transfer to information exchange in health and health care. Soc Sci Med. 2003;56(3): 449-464.

89. Balcou-Debussche M, Debussche X. Type 2 diabetes patient education in Reunion Island: Perceptions and needs of professionals in advance of the initiation of a primary care management network. Diabetes Metab. 2008;34(4 Pt 1):375-381.

90. Bodenheimer T, Handley MA. Goal-setting for behavior change in primary care: an exploration and status report. Patient Educ Couns. 2009;76(2):174-180.

91. Balcou-Debussche M. L'éducation des malades chroniques. Une approche ethnosociologique. [Patient education in chronic illness, an ethnosociological approach]. Paris: Éditions des Archives Contemporaines; 2006. French.

92. Bril B. Apprentissage et contexte [Learning and context]. Intellectica. 2002;35:251-268. French. 
93. Gibson JJ. The theory of affordances. In: Shaw R, Bransford J, editors. Perceiving, Acting and Knowing. Hillsdale, NJ: Lawrence Erlbaum Associates; 1977:67-82.

94. Lahire B. L'homme pluriel. Les ressorts de l'action. [The plural actor]. Paris: Nathan; 1998. French.

95. Thievenaz J, Tourette-Turgis C, Khaldi C. Analyser le "travail" du malade. Nouveaux enjeux pour la formation et la recherche en éducation thérapeutique. [Analyzing the "work" of the patient. Novel challenges for the education and research in therapeutic patient education"] Education Permanente. 2013;195(2):47-58. French.

96. Durkheim E. Education and sociology. Glencoe, IL: The Free Press; 1956.

97. Jodelet D. Place de l'expérience vécue dans les processus de formation des représentations sociales. [Individual experiences and social representations in training and education processes]. In: Haas V, editor. Les savoirs du quotidien. Transmission, appropriations, représentations. [Knowledge from daily life. Transmission, appropriation, representation]. Rennes: Presses universitaires de Rennes; 2006:235-255. French.

98. d'Ivernois JF, Gagnayre R. Apprendre à éduquer le patient: Approche pédagogique. [Learn to educate the patient: pedagogical approach]. Paris: Maloine; 2011. French.

99. Stone MA, Patel N, Daly H, et al. Using qualitative research methods to inform the development of a modified version of a patient education module for non-English speakers with type 2 diabetes: experience from an action research project in two South Asian populations in the UK. Diversity in Health and Social Care. 2008;5(3):199-206.

100. Debussche X, Balcou-Debussche M. [Combining biomedical and psychosocial approaches for the framing of learning sessions in therapeutic patient education]. Medecine Maladies Metaboliques. 2011;5(2):180-185. French.

101. Burke S, Sherr D, Lipman RD. Partnering with diabetes educators to improve patient outcomes. Diabetes Metab Syndr Obes. 2014;7: 45-53.

102. Kadirvelu A, Sadasivan S, Ng SH. Social support in type II diabetes care: a case of too little, too late. Diabetes Metab Syndr Obes. 2012;5: 407-417.

103. Seale C, Rivas C, Al-Sarraj H, Webb S, Kelly M. Moral mediation in interpreted health care consultations. Soc Sci Med. 2013;98: 141-148.
104. Dettori N, Flook BN, Pessl E, et al. Improvements in Care and Reduced Self-management Barriers Among Rural Patients With Diabetes. J Rural Health. 2005;21(2):172-177.

105. Balcou-Debussche M. Inscription sociale de 1'ETP, hétérogénéité et vulnérabilité des personnes. Analyse de résultats obtenus en contexte pluriel, à Mayotte. [Social inscription of TPE, heterogeneity and patient's vulnerability. Analysis of results obtained in the plural context of Mayotte]. Ther Patient Educ. 2013;5(1):113-121. French.

106. Gordon K, Smith F, Dhillon S. Effective chronic disease management: patients' perspectives on medication-related problems. Patient Educ Couns. 2007;65(3):407-415.

107. Stock S, Drabik A, Buscher G, et al. German diabetes management programs improve quality of care and curb costs. Health Aff (Millwood). 2010;29(12):2197-2205.

108. Bodenheimer T. Planned visits to help patients self-manage chronic conditions. Am Fam Physician. 2005;72(8):1454-1456.

109. Chew-Graham Ca, Hunter C, Langer S, et al. How QOF is shaping primary care review consultations: a longitudinal qualitative study. BMC Fam Pract. 2013;14:103

110. Blackberry ID, Furler JS, Best JD, et al. Effectiveness of general practice based, practice nurse led telephone coaching on glycaemic control of type 2 diabetes: the Patient Engagement and Coaching for Health $(\mathrm{PEACH})$ pragmatic cluster randomised controlled trial. BMJ. 2013;347:f5272.

111. Kielmann T, Huby G, Powell A, et al. From support to boundary: a qualitative study of the border between self-care and professional care. Patient Educ Couns. 2010;79(1):55-61.

112. Langer S, Chew-Graham C, Hunter C, Guthrie EA, Salmon P. Why do patients with long-term conditions use unscheduled care? A qualitative literature review. Health Soc Care Community. 2013;21(4):339-351.

113. Sieber W, Newsome A, Lillie D. Promoting self-management in diabetes: efficacy of a collaborative care approach. Fam Syst Health. 2012;30(4):322-329.

114. Kennedy A, Rogers A, Bower P. Support for self care for patients with chronic disease. BMJ. 2007;335(7627):968-970.

\section{Publish your work in this journal}

Diabetes, Metabolic Syndrome and Obesity: Targets and Therapy is an international, peer-reviewed open-access journal committed to the rapid publication of the latest laboratory and clinical findings in the fields of diabetes, metabolic syndrome and obesity research. Original research, review, case reports, hypothesis formation, expert opinion and commentaries are all considered for publication. The manuscript management system is completely online and includes a very quick and fair peer-review system, which is all easy to use. Visit http://www.dovepress.com/testimonials.php to read real quotes from published authors. 